Eur. J. Clin. Chem. Clin. Biochem.

Vol. 32, 1994, pp. 929-933

(c) 1994 Walter de Gruyter \& Co.

Berlin - New York

\title{
Recovery of Cholesterol and Triacylglycerol in Very-Fast Ultracentrifugation of Human Lipoproteins in a Large Range of Concentrations
}

\author{
By W. Leonhardt, J. Pietzsch, U. Julius and M. Hanefeld
}

Abteilung Klinische Stoffwechselforschung, Medizinische Fakultät „Carl Gustav Carus" der Technischen Universität Dresden, Dresden, Germany

(Received May 5/August 10, 1994)

Summary: Very-fast ultracentrifugation using a benchtop ultracentrifuge was applied to the analysis of lipoproteins in $0.5 \mathrm{ml}$ of human plasma. VLDL, IDL and LDL were flotated at densities of $1.006,1.019$ and $1.063 \mathrm{~kg} / \mathrm{l}$ in runs lasting 30,100 and 100 minutes. Chylomicrons, if present, were flotated in a separate run. HDL were isolated by precipitation of the apolipoprotein B-containing lipoproteins from total plasma using polyethylene glycol. Three series of separations were routinely performed: 1. VLDL run alone (632 samples), 2. VLDL run + LDL run (122 samples), and 3. Chylomicron separation + VLDL run + IDL run (92 samples). The concentrations of cholesterol and triacylglycerol were obtained for plasma, chylomicrons, VLDL, IDL, LDL and HDL. Plasma values ranged from 1.8 to $37.1 \mathrm{mmol} / 1$ cholesterol and 0.26 to $50.2 \mathrm{mmol} / 1$ triacylglycerol. The plasma triacylglycerol concentrations were corrected for free glycerol by $3 \%$ (for triacylglycerols $<2.5 \mathrm{mmol} / \mathrm{l}$ ) and by $2 \%$ (for triacylglycerols $\geqq 2.5 \mathrm{mmol} / \mathrm{l}$ ). The recovery rate of lipids after ultracentrifugation was determined by comparing the concentrations in lipoproteins and in plasma. It was near to $100 \%$ and decreased for samples with extremely high lipid concentrations.

\section{Introduction}

Separation of lipoproteins of human plasma by ultracentrifugation can now be accomplished in a short time and starting with small samples, by use of vertical rotors (1), a benchtop ultracentrifuge $(2-7)$, or density gradients $(1,6,8)$. In "very-fast ultracentrifugation" (9) using a benchtop ultracentrifuge at $120000 \mathrm{~min}^{-1}$, the centrifugal field reaches $625000 \mathrm{~g}$ which is about three times more than in classical ultracentrifugation. There are only minimal differences in the apparent lipid concentrations of lipoproteins separated by very-fast ultracentrifugation in comparison to conventional ultracentrifugation at $30000 \mathrm{~min}^{-1}$. As an advantage, VLDL, IDL and $\mathrm{LDL}^{1}$ )

\footnotetext{
1) Abbrevations: VLDL $=$ very-low density lipoproteins,

$\mathrm{LDL}=$ low-density lipoproteins,

$\mathrm{IDL}=$ intermediate-density lipoproteins,

$\mathrm{HDL}=$ high-density lipoproteins,

$\mathbf{s}_{\mathbf{f}}=$ flotation (sedimentation) constant in Svedberg units $\left(10^{-13}\right.$ seconds)
}

are obtained albumin-free. The literature data cited were obtained on small numbers of samples, or within narrow limits of lipid concentrations. The aim of the present paper was therefore to study the recovery of cholesterol and triacylglycerol in separated lipoproteins in a large range of concentrations. 819 plasma samples were processed by very-fast ultracentrifugation.

\section{Materials and Methods}

Plasma samples and separation strategy (tab. 1)

Blood samples were taken by venipuncture after an overnight fast and collected into evacuated tubes (Red monovette, Sarstedt, Nümbrecht-Rommelsdorf, Germany) containing $1.2-2 \mathrm{~g}$ of $\mathrm{K}_{2}$-EDTA per litre as an anticoagulant and antioxidant. Plasma was obtained by centrifugation ( 6 minutes at $2500 \mathrm{~g}$ ) at room temperature. Chylomicrons were separated from the fresh plasma if necessary. The material was stored for maximally five days at 4 to $8^{\circ} \mathrm{C}$ before ultracentrifugation. Three types of separation were routinely performed: 
Tab. 1 Flow sheet of separation procedures

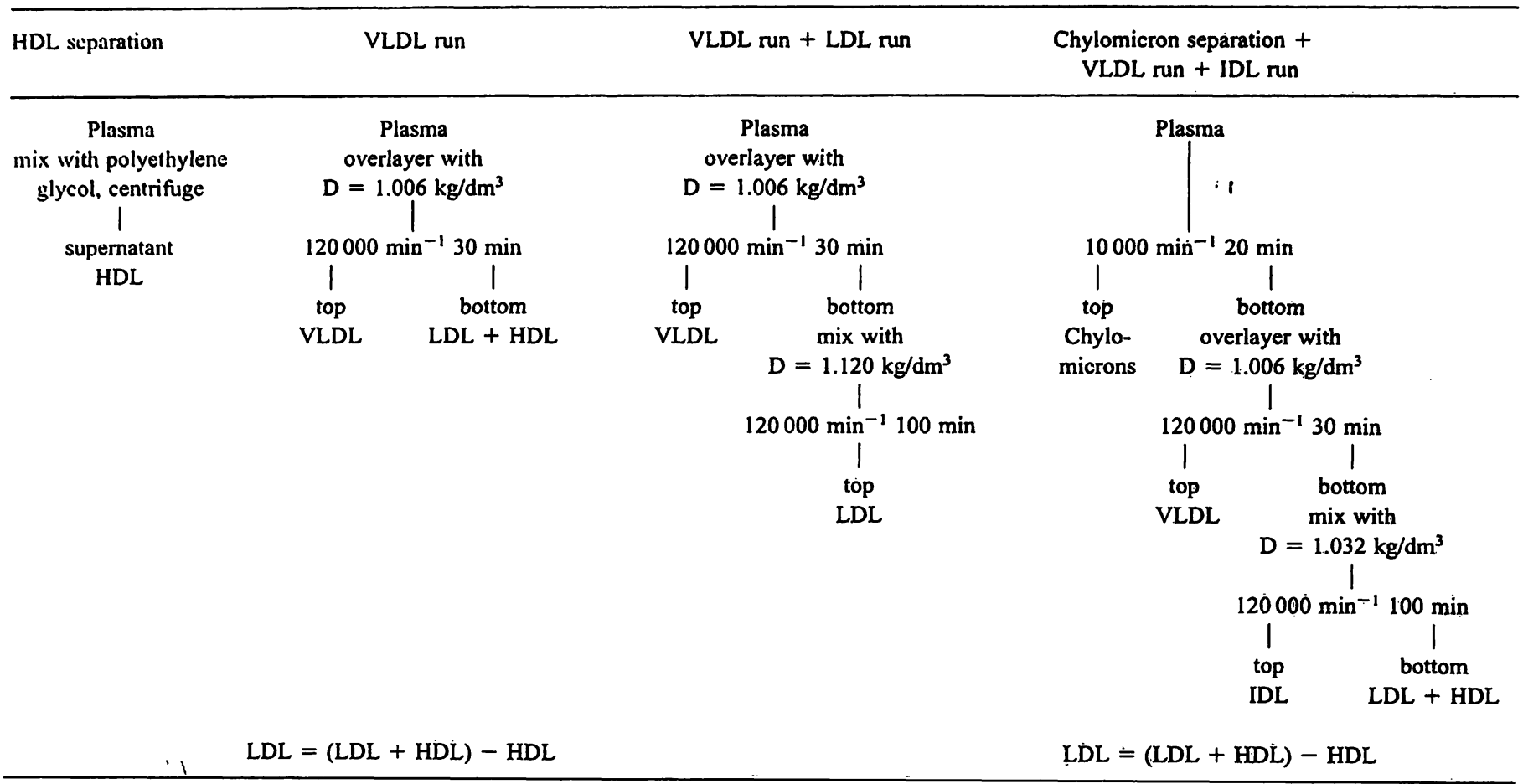

1. VLDL run alone (632 samples with $1.8-15.8 \mathrm{mmol} / 1$ cholesterol and $0.26-46.4 \mathrm{mmol} / \mathrm{l}$ triacylglycerol)

2. VLDL run followed by LDL run (122 samples with $2.6-18.2$ $\mathrm{mmol} / \mathrm{l}$ cholesterol and $0.59-13.0 \mathrm{mmol} / 1$ triacylglycerol)

3. Chylomicron separation followed by VLDL run and by IDL run (92 samples with 3.4-37.1 $\mathrm{mmol} / 1$ cholesterol and $1.8-50.2$ $\mathrm{mmol} / \mathrm{l}$ triacylglycerol). In all samples, HDL were isolated from total plasma by precipitation using polyethylene glycol.

\section{Separation of chylomicrons}

Chylomicrons were separated if one of the following criteria were fulfilled:

\section{Triacylglycerol concentration above $7 \mathrm{mmol} / \mathrm{l}$}

\section{Lipaemic plasma or}

\section{History of chylomicronaemia.}

Plasma $\left(5 \mathrm{ml}\right.$ ) was centrifuged at $20^{\circ} \mathrm{C}$ and $19000 \mathrm{~min}^{-1}$ (centrifugal field $=11000 \mathrm{~g}$ ) for 20 minutes including 4 minutes for acceleration and deceleration. The conditions were adequate to complete flotation of $s_{f}=400$ particles. The chylomicron-free plasma was carefully aspirated using a syringe with wide needle. The further ultracentrifugation programme included separation of IDL (see below).

\section{Very-fast ultracentrifugation}

We used the Optima ${ }^{\mathrm{TM}}$ TLX Ultracentrifuge with rotor TLA-120.2 $\left(r_{\max }=38.9 \mathrm{~mm}, r_{\min }=24.5 \mathrm{~mm}\right)$, thickwall polycarbonate tubes \# 343778 (volume $=1 \mathrm{ml}$, for use without cap) and CentriTube Slicer (Beckman Instruments Inc). The runs were driven at $20^{\circ} \mathrm{C}$ and at full speed of $120000 \mathrm{~min}^{-1}$ which corresponds to a centrifugal field of $625000 \mathrm{~g}$. For isolation of VLDL, $0.500 \mathrm{ml}$ of EDTAplasma were overlayered with $0.500 \mathrm{ml}$ of solution with density $\mathrm{D}=1.006 \mathrm{~kg} / \mathrm{l}$. The mass of the tube content was determined by weighing. After centrifugation for 30 minutes, the tubes were sliced to yield about $0.550 \mathrm{ml}$ of top and $0.450 \mathrm{ml}$ of bottom fraction. Both fractions were carefully drawn off with a pipet. If necessary, recovery of the top fraction was completed by washing with additional volume of density medium. The accurate masses of both fractions were determined by weighing. For flotation of LDL at density $\mathrm{D}=1.063 \mathrm{~kg} / \mathrm{l}, 0.500 \mathrm{ml}$ of the bottom fraction were mixed with $0.470 \mathrm{ml}$ of solution with density $D=1.120 \mathrm{~kg} / \mathrm{l}$ in a second centrifuge tube. The mass of the tube contents was measured. After centrifugation for 100 minutes, slicing and weighing were performed as before. Alternatively, for flotation of IDL at density $\mathrm{D}=1.019 \mathrm{~kg} / \mathrm{l}, 0.500 \mathrm{ml}$ of the bottom fraction of VLDL run were mixed with $0.470 \mathrm{ml}$ of solution with density $\mathrm{D}=1.032$ $\mathrm{kg} / \mathrm{l}$. After slicing as described above, the bottom fraction was analyzed for LDL + HDL. The concentrations of cholesterol and triacylglycerol were determined in the top and bottom fractions. From the apparent concentrations ('), the lipid concentrations in the lipoproteins were calculated considering the type of separation:

$$
\mathrm{VLDL}=\mathrm{VLDL}^{\prime} \cdot\left(2 \cdot \mathrm{m}_{2} / \mathrm{m}_{1}\right)
$$

VLDL run exclusively:

$$
(\mathrm{LDL}+\mathrm{HDL})=(\mathrm{LDL}+\mathrm{HDL})^{\prime} \cdot\left(2 \cdot \mathrm{m}_{3} / \mathrm{m}_{1}\right)
$$

VLDĹ run + LDL run:

$$
\mathrm{LDL}=\mathrm{LDL}^{\prime} \cdot\left(2 \cdot \mathrm{m}_{3} / \mathrm{m}_{1}\right) \cdot\left(2 \cdot \mathrm{m}_{5} / \mathrm{m}_{4}\right)
$$

Chylomicron run + VLDL run + IDL run:

$$
\begin{aligned}
& \mathrm{IDL}=\mathrm{IDL} \cdot\left(2 \cdot \mathrm{m}_{3} / \mathrm{m}_{1}\right) \cdot\left(2 \cdot \mathrm{m}_{5} / \mathrm{m}_{4}\right) \\
& (\mathrm{LDL}+\mathrm{HDL})=(\mathrm{LDL}+\mathrm{HDL})^{\prime} \cdot\left(2 \cdot \mathrm{m}_{3} / \mathrm{m}_{1}\right) \cdot\left(2 \cdot \mathrm{m}_{6} / \mathrm{m}_{4}\right)
\end{aligned}
$$

$\mathrm{m}_{1}$ : total mass in first (VLDL) run,

$\mathrm{m}_{2}$ : top (inclusive wash solution) mass,

$\mathrm{m}_{3}$ : bottom mass after first run,

$\mathrm{m}_{4}$ : total mass in second (IDL or LDL, resp.) run, $\mathrm{m}_{\mathrm{s}}$ : top mass,

$\mathrm{m}_{6}$ : bottom mass after second run.

In fact, the volume ratio $v_{a} / v_{b}\left(v_{a}=\right.$ volume after slicing, $v_{b}=$ volume before ultracentrifugation $=0.5 \mathrm{ml}$ ) of the analyte was considered; for instance, VLDL/VLDL' $=\mathrm{v}_{\mathrm{a}} / \mathrm{v}_{\mathrm{b}}=\mathrm{m}_{2} /\left(\mathrm{m}_{1} \cdot 0.5\right)$ $=2 \cdot \mathrm{m}_{2} / \mathrm{m}_{1}$. Typical values were: $\mathrm{m}_{1}=1020 \mathrm{mg}, \mathrm{m}_{2}=450 \mathrm{mg}$, $\mathrm{VLDL} / \mathrm{VLDL} \mathrm{L}^{\prime}=0.8824$. The density media were prepared as follows: 
Solution 1. $\mathrm{D}=1.006 \mathrm{~kg} / \mathrm{l}, \mathrm{pH}=9.18: 11.4 \mathrm{~g} \mathrm{NaCl}+0.1 \mathrm{~g}$ EDTA- $\mathrm{Na}+\mathrm{H}_{2} \mathrm{O}$ ad $11+1 \mathrm{ml} \mathrm{NaOH} 1 \mathrm{~mol} / \mathrm{l}$.

Solution 2. $\mathrm{D}=1.182 \mathrm{~kg} / \mathrm{l}, \mathrm{pH}=7.32: 124.9 \mathrm{~g} \mathrm{NaBr}+$ solution 1. ad $500 \mathrm{ml}$.

Solution 3. $\mathrm{D}=1.032 \mathrm{~kg} / \mathrm{l}, \mathrm{pH}=8.26: 50 \mathrm{ml}$ solution $1 .+8.7$ $\mathrm{ml}$ solution 2 .

Solution 4. $\mathrm{D}=1.120 \mathrm{~kg} / \mathrm{l}, \mathrm{pH}=7.38: 50 \mathrm{ml}$ solution $1 .+92$ $\mathrm{ml}$ solution 2 .

The densities were determined using the oscillator device DMA 602 (Anton Paar AG, Graz, Austria).

\section{Other analyses}

HDL were isolated from total plasma using a $95 \mathrm{~g} /$ polyethylene glycol 20000 solution in phosphate buffer, $\mathrm{pH}=6.5$ (10). This reagent precipitates apolipoprotein B containing lipoproteins and also yields quantitative separation in lipaemic samples. When no LDL run was performed, lipid concentrations in LDL were calculated as the difference of concentrations of the infranatant of either VLDL or IDL run (= LDL + HDL) and HDL (11). The concentrations of cholesterol and triacylglycerol in whole plasma were determined by enzymatic reactions (CHOD-PAP method, GPO-PAP method) using commercial test kits (Boehringer Mannheim) on a 550 Express Analyzer (Ciba Corning). Analyses on lipoprotein solutions after ultracentrifugation were done in the same way. Measurements of low concentrations (triacylglycerol in LDL and in $\mathrm{HDL}$, cholesterol in VLDL and in HDL) were performed with tenfold increased sample to reagent ratio. Calibration and control samples were in this case applied at the same ratio. Samples with very high lipid concentrations were diluted. The day-to day imprecision of lipid determinations was on the order of $1.5 \%$ for cholesterol and $2.5 \%$ for triacylglycerol.

\section{Glycerol correction}

The triacylglycerol test kit provided the sum of acyl glycerides and free glycerol. Correction was necessary to make the triacylglycerol in plasma and in lipoproteins comparable. Therefore, the concentration of free glycerol was tested in 63 randomly selected plasma

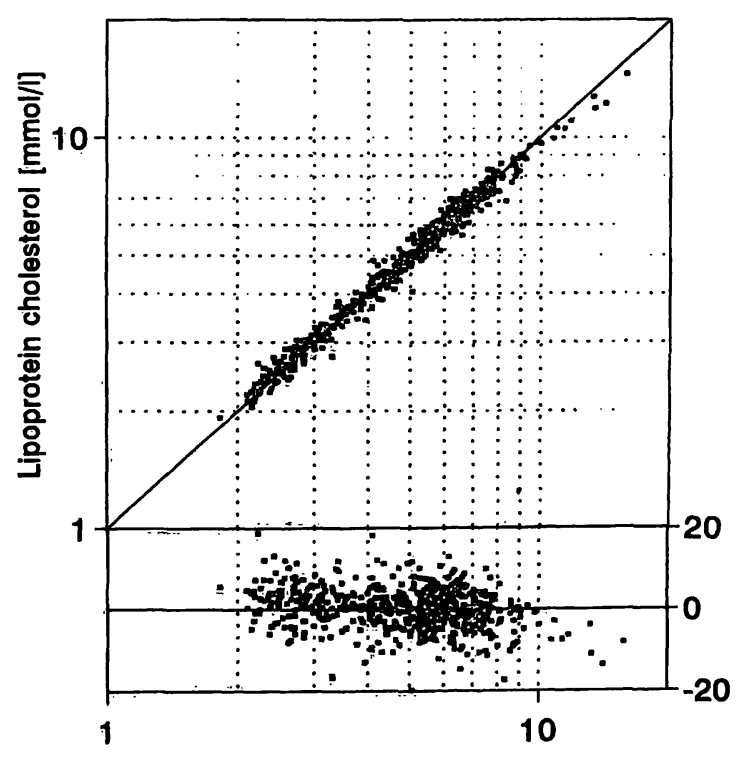

Plasma cholesterol [mmol/l]

Fig. 1 Recovery of cholesterol (logarithmic scale) after VLDL run $(n=632)$.

Lower part: bias $(\%)=$ (lipoprotein cholesterol/plasma cholesterol) $\cdot 100-100$. samples by the UV test initiated with glycerokinase. Before the test, the plasma was cleared by precipitation with trichloroacetic acid: The test combination triacylglycerol (Boehringer Mannheim) was used. We found a significant relationship (correlation coefficient $r=0.273, p<0.030$ ) between the concentrations of free glycerol and triacylglycerol. Based on this, the plasma triacylglycerol was approximately corrected by $2 \%$ for concentrations $>=2.5 \mathrm{mmol} / \mathrm{l}$ and by $3 \%$ for concentrations $<2.5 \mathrm{mmol} / 1$.

\section{Results}

Lipoprotein lipid concentrations were calculated as the sum of the lipid concentrations in the lipoproteins. They were compared to the plasma lipid concentrations. There were good correlations in the three types of analyses performed: for VLDL runs alone (figs. 1 and 2), for the combination of VLDL and LDL runs (fig. 3 ) and for the combination of chylomicron, VLDL and IDL runs (figs. 4 and 5). As outlined in the methods section, analysis of HDL by precipitation influenced the sum of lipoprotein lipids only in the combination of VLDL and LDL runs, while in the other types of analyses the sum was calculated using (LDL $+\mathrm{HDL})$. The recovery of cholesterol and triacylglycerol is summarized in table 2 . The bias (=100 - recovery; lower part of the figures) was generally symmetrical to zero in low and medium lipid concentrations but tended to become negative for cholesterol and triacylglycerol concentrations above $7 \mathrm{mmol} / \mathrm{l}$. The bias was calculated immediately after every analysis. When it exceeded $\pm 20 \%$, the analysis was repeated. This was necessary in $18(2.8 \%)$ VLDL runs, in 3 (2.5\%) VLDL plus LDL runs, and in $6(6.5 \%)$ chylomicron plus VLDL plus IDL runs.

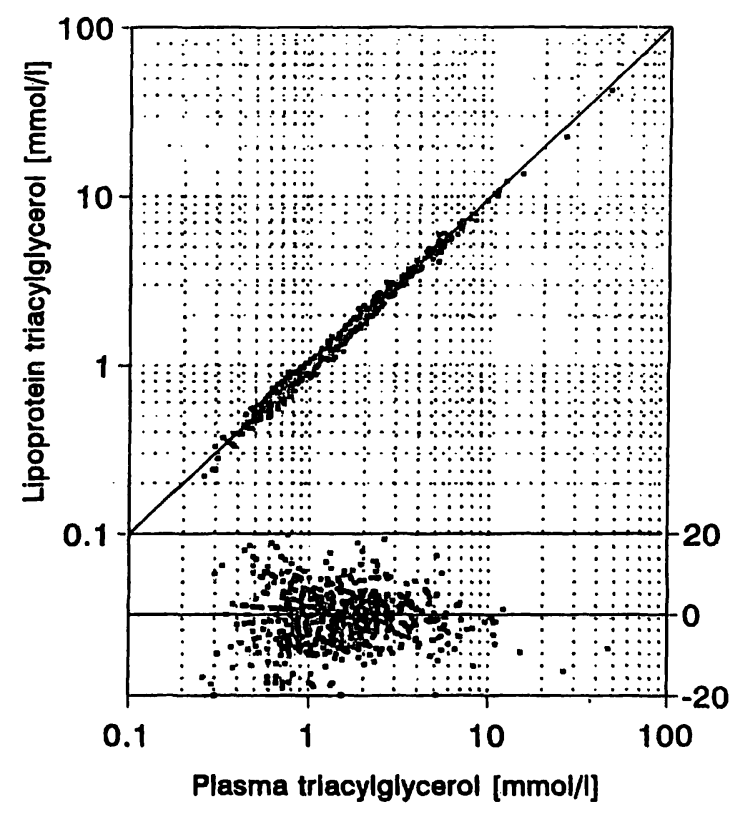

Fig. 2 Recovery of triacylglycerol (logarithmic scale) after VLDL run $(n=614)$.

Lower part: bias $(\%)=($ lipoprotein triacylglycerol/plasma triacylglycerol) $\cdot 100-100$. 


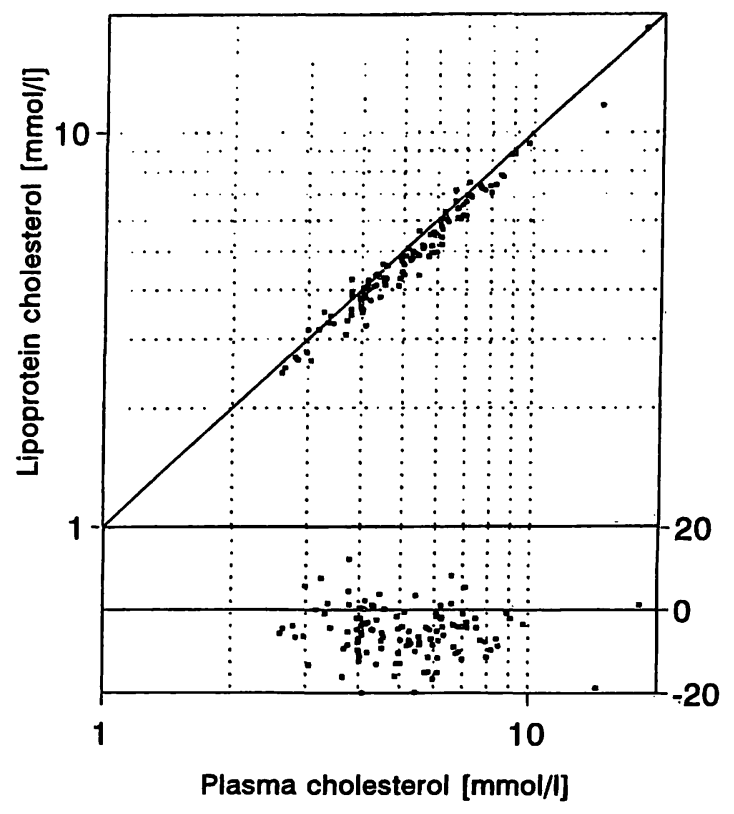

Fig. 3 Recovery of cholesterol (logarithmic scale) after VLDL plus LDL runs $(n=119)$.

Lower part: bias $(\%)=$ (lipoprotein cholesterol/plasma cholesterol) $\cdot 100-100$.

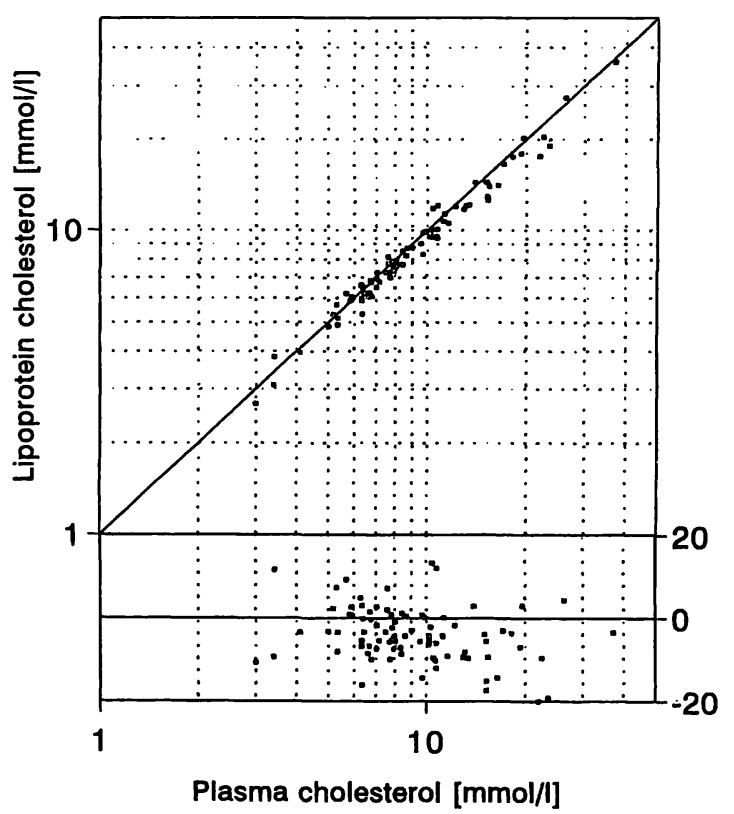

Fig. 4 Recovery of cholesterol (logarithmic scale) after chylomicron plus VLDL plus IDL runs $(n=86)$.

Lower part: bias $(\%)=$ (lipoprotein cholesterol/plasma cholesterol) $\cdot 100-100$.

\section{Discussion}

It can be estimated by calculation that the short run periods we chose were sufficient to achieve the separations at the midpoint of the tubes. Concerning the VLDL run, 30 minutes were enough for all light lipoproteins to flotate into the upper half of the tubes. LDL was not expected to sediment since the plasma was overlayered with the medium. In contrast, before the IDL and LDL runs the density media were added by mixing. The separation quality was in these cases critically dependent on sedimentation of the heavier lipoproteins. The run time of 100 minutes corresponded to $\mathrm{s}_{\mathrm{f}}=2.1$ for flotation and $s_{\mathrm{f}}=2.8$ for sedimentation at the midpoint of the tube, i. e., it was sufficient for the expected lipoprotein separations. The recovery of lipoprotein lipids approached $100 \%$ in low and medium lipid concentrations while it became lower in extremely high lipid concentrations.

Comparable data on the recovery rate were only given by one other group (6). The good recovery was based on the slicing technique combined with washing steps. The calculation of the lipoprotein lipid concentrations

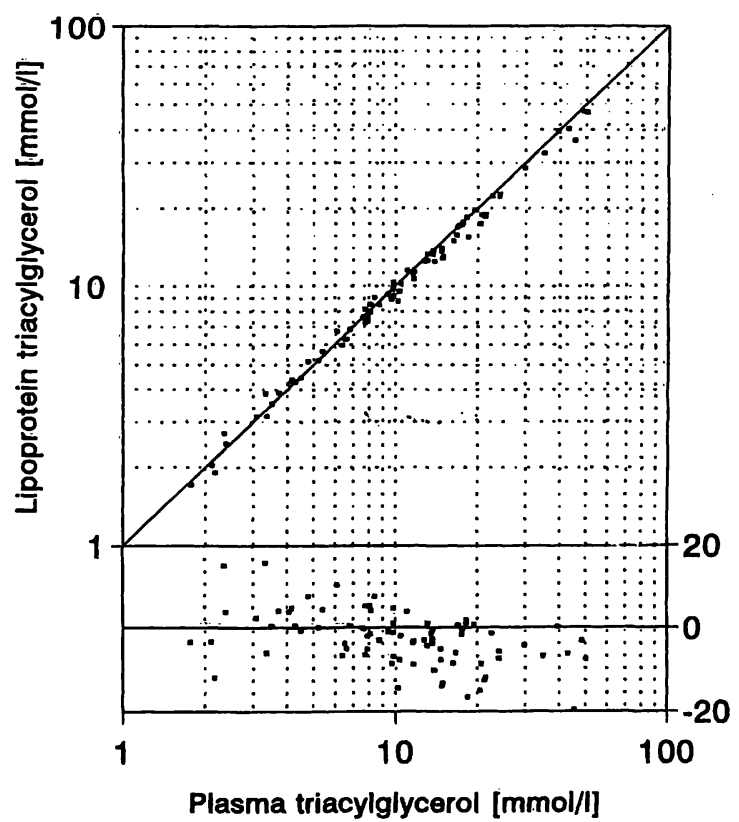

Fig. 5 Recovery of triacylglycerol (logarithmic scale) after chylomicron plus VLDL plus IDL runs $(n=82)$.

Lower part: bias $(\%)=$ (lipoprotein triacylglycerol/plasma triacylglycerol) $\cdot 100-100$.

Tab. 2 Mean recovery (\%) of cholesterol and triacylglycerols

\begin{tabular}{llllll}
\hline & \multicolumn{2}{l}{ Triacylglycerol } & & \multicolumn{2}{l}{ Cholesterol } \\
\cline { 2 - 3 } \cline { 5 - 6 } & Mean & $95 \%$ tolerance interval & & Mean & $95 \%$ tolerance interval \\
\hline VLDL run & 100.1 & $91.5-108.6$ & 99.2 & $87.4-111.0$ \\
VLDL + LDL run & 94.4 & $83.5-105.4$ & n.d. & $85.1-109.6$ \\
Chylomicron + VLDL + IDL run & 96.0 & $83.7-108.4$ & 97.4 & \\
\hline
\end{tabular}

n. d. $=$ not detected 
from the apparent concentrations was based on weighing which was much more accurate and time-saving than volume measurements. In the case of triacylglycerol, the recovery was dependent on the glycerol correction. We found the recommended correction by $0.12 \mathrm{mmol} / \mathrm{l}$ inadequate, namely in the case of very low triacylglycerol concentrations. Instead of this, we used corrections of $3 \%$ below and $2 \%$ above the level of $2.5 \mathrm{mmol} / \mathrm{l}$ triacylglycerol.

The proposed method of very-fast ultracentrifugation has the advantage of being fast. It yields nearly complete

\section{References}

1. Chung, B. H., Segrest, J. P., Ray, M. J., Brunzell, J. D., Hokanson, J. E., Krauss, R. M., Beaudrie, K. \& Cone, J. T. (1986) Single vertical spin density gradient ultracentrifugation. In: Methods in Enzymology Vol 128: Plasma Lipoproteins (Segrest, J. P. \& Albers, J. J., eds.) pp. 181-209, Orlando etc: Academic Press.

2. David, J. A., Paksi, J. \& Naito, H. K. (1986) Separation of lipoprotein (Lp) fractions by the Beckman TL-100 table-top ultracentrifuge (UC). Clin. Chem. 32, 1094.

3. Wu, L. L., Warnick, G. R., Wu, J. T., Williams, R. R. \& Lalouel, J. M. (1989) A rapid micro-scale procedure for determination of the total lipid profile. Clin. Chem. 35, 1486-1491.

4. Cathcart, S. \& Dominiczak, M. H. (1990) The measurement of lipoprotein subfractions in plasma using a tabletop ultracentrifuge. Ann. Clin. Biochem. 27, 459-464.

5. Gebhardt, D. O. E. \& Molenaar, A. J. (1992) Quantitative determination of plasma lipoproteins. Letter to the editor. Ann. Clin. Biochem. 29, 115.

6. Brousseau, T., Clavey, V., Bard, J. M. \& Fruchart, J. C. (1993) Sequential ultracentrifugation micromethod for separation of serum lipoproteins and assay of lipids, apolipoproteins, and lipoprotein particles. Clin. Chem. 39, 960-964.

7. Fletcher, C. D., Barnes, J. F., Farish, E. (1994) A rapid semimicro method for the separation of lipoprotein fractions that uses a benchtop ultracentrifuge. Clin. Chim. Acta 226, 95-99. recovery of lipoproteins. It requires only $0.5 \mathrm{ml}$ of plasma sample which can have lipid concentrations ranging from extremely low to extremely high.

\section{Acknowledgements}

The authors wish to thank Mrs. Regina Bergmann, Ingeborg Heidrich, Sigrid Nitzsche and Bärbel Zeiler for their skillful technical assistance. This work was in part supported by project No. $07 \mathrm{NBL}$ 03 "Differentiation of the atherosclerosis risk in familial combined hyperlipidemia and hypertension" of the Bundesministerium für Forschung und Technologie.

8. Kleinveld, H. A., Hak-Lemmers, H. L. M., Stalenhoef, A. F. H. \& Demaker, P. N. M. (1992) Improved measurement of low-density-lipoprotein susceptibility to copper-induced oxidation: Application of a short procedure for isolation of lowdensity lipoprotein. Clin. Chem. 38, 2066-2072.

9. Leonhardt, W., Pietzsch, J. \& Nitzsche, S. (1994) Very-fast ultracentrifugation of human plasma lipoproteins. Influence of the centrifugal field on lipoprotein composition. Clin. Chim. Acta 224, 21-32.

10. Kostner, G. M., Molinari, E. \& Pichler, P. (1985) Evaluation of a new HDL2/HDL3 quantitation method based on precipitation with polyethylene glycol. Clin. Chim. Acta 148, 139-147.

11. Manual of laboratory operations (1974) Lipid Research Clinics Program. Vol 1, Lipid and Lipoprotein Analysis. Bethesda MD: National Institutes of Health, NHLBI, DHEW publication no. $75-628$.

Prof. Dr. W. Leonhardt

Department of Clinical Metabolic Research Medical Faculty Carl Gustav Carus of the Technical University Dresden

Fetscherstraße 74

D-01307 Dresden

Germany 
